\title{
The effect of textured surfaces on the hydrodynamic pressure generation in journal bearings
}

\author{
Muchammad ${ }^{1,2, *}$, Mohammad Tauviqirrahman ${ }^{1}$, Rizqy Amanullah Akbar $^{1}$, Fuad Hilmy $^{1}$ and \\ Jamari $^{1}$ \\ ${ }^{1}$ Laboratory for Engineering Design and Tribology, Department of Mechanical \\ Engineering, University of Diponegoro, 50275 Semarang, Indonesia \\ ${ }^{2}$ Laboratory for Surface Technology and Tribology, Faculty of Engineering Technology, University of \\ Twente, Netherlands. Drienerloolan 5, Postbus 217, 7500 AE, Enschede, The Netherlands
}

\begin{abstract}
Surface texturing of the lubricated bearing has proven to improve the hydrodynamic performance. The present paper analyzed the effect of surface texturing on the covergent journal bearing with computational fluid dynamic (CFD) approach. The eccentricity ratio, the ratio of textured depth and surface area are the main parameter research. It was shown that for the eccentricity ratio of 0.2 , the surface texturing improves the hydrodynamic performance lubrication by increasing the load support. On the otherwise, for the eccentricity ratio of 0.8 , the surface texturing does not improve the lubrication performance, even under certain condition, it decreases the lubrication performance of journal bearing.
\end{abstract}

\section{Introduction}

Surface texturing is an effective approach to increase the tribological performance of lubricated mechanical components. It is known that by introducing textured surfaces it significantly can affect friction and load support of lubricated contacts. It was shown experimentally that such texturing enhances load support and reduces hydrodynamic friction for instance systems with reciprocating (cylinder-liner) contacts [1] mechanical seals [2] and two parallel sliding surfaces [3-4].

Lately, studies have proven that surface texturing can be beneficial, experimentally and/or theoretically [5-6]. Its main influence is to enhance hydrodynamic pressure distribution, and it results in a higher load support of the lubricated contact.

Dobrica and Fillon [5] researched the texture aspect ratio and Reynolds number had an equally significant effect on the validity of the Reynolds equation in analyzing a textured contact. More investigations on the interaction of fluid inertia with surface texture in a plain sliding contact was shown by Cupillard et al. [6]. Their results indicated that inertia effects can produce either negative or positive influence on the load support of a textured surface. Recently, Yuan et al. [7] experimentally showed that the orientation of a micro-texture has a strong effect on the friction performance of a sliding contact. Experimentally, Yagi at al

\footnotetext{
*Corresponding author: m_mad5373@yahoo.com
} 
[8] found that the formation of micro-texture on the surface of paper-friction materials can improve the dynamic friction coefficient by changing the groove volume ratio and without changing the pore characteristics of the paper. Numerically, Yagi et al [9] investigated the magnitude of the load-carrying capacity enabled by textured feature in hydrodynamic lubrication based on Reynolds equation.

The present paper investigates the effect of texturing using CFD model based on Navier-Stokes in journal bearing. In particular, the investigation is focused on the generation of the pressure distribution and the load support. The variation of surface texturing, the ratio of eccentricity, and the ratio of texture depth are of particular interest.

\section{Methodology}

\subsection{CFD Model}

Figure 1 depicts the schematic and details of surface texturing on journal bearing. In the fist case, surface texturing is applied in convergent area $\left(0^{\circ}-48^{\circ}\right)$, and referred as texture 1 . Texture 2 is denoted with texturing placed on $122^{\circ}-170^{\circ}$ area. The main characteristics of the journal bearing and the lubricant properties are presented in Table 1. Hydrodynamic lubrication performance especially pressure distribution and load support are the main focus of research. In the present study, the ratio of texture depth is varied by $0.34,1.00$ (shallow groove) and 4.4, 6.00 (deep groove) to improve the hydrodynamic performance. In addition, the eccentricity ratio also became the focus of the study. In this research focus on the eccentricity ratio of 0.2 and 0.8 respectively.
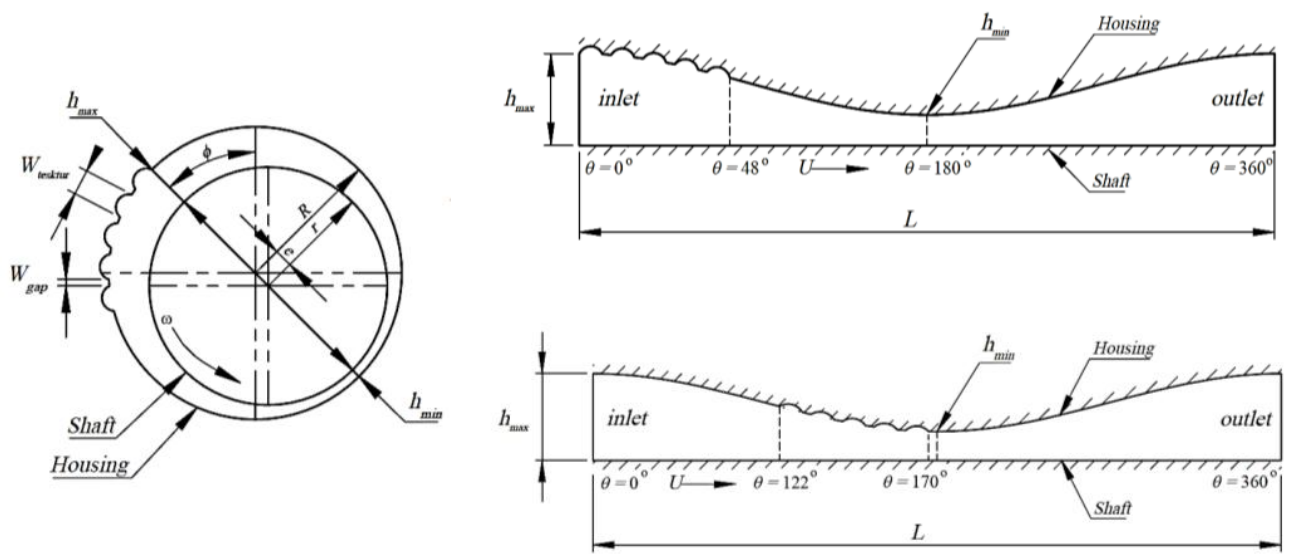

Fig. 1. Schematic of texture in journal bearing. 
Table 1. The main parameters of journal bearing.

\begin{tabular}{|c|c|c|}
\hline Parameter & Data Setting & Unit \\
\hline Shaft radius, $r$ & 39.94 & $\mathrm{~mm}$ \\
\hline Housing radius, $R$ & 40 & $\mathrm{~mm}$ \\
\hline Radial clearance, $C$ & 0.06 & $\mathrm{~mm}$ \\
\hline The ratio of eccentricity, $\varepsilon$ & $0.2 ; 0.8$ & - \\
\hline Eccentricity, $e$ & $0.012 ; 0.048$ & $\mathrm{~mm}$ \\
\hline Shaft rotation, $\omega$ & 1000 & $\mathrm{rpm}$ \\
\hline Lubricant density, $\rho$ & 998.2 & $\mathrm{~kg} / \mathrm{m}^{3}$ \\
\hline Lubricant viscosity, $\mu$ & 0.001 & $\mathrm{~kg} / \mathrm{ms}$ \\
\hline The ratio of texture depth, $d / h_{\min }$ & $0.34 ; 1.00 ; 4.40 ; 6.00$ & - \\
\hline Texture area; Texture 1 & $0-48$ & ${ }^{\circ}$ \\
Texture 2 & $122-170$ & $\mathrm{o}$ \\
\hline
\end{tabular}

\subsection{Theory}

In the present study, the lubrication problem is solved by the Navier-Stokes equation and continuity equations. The Navier-Stokes (N-S) equations are solved over the domain using a finite-volume method with the commercial CFD software package FLUENT ${ }^{\circledR}$. The Navier-Stokes and the continuity equations can be expressed, respectively.

$$
\begin{gathered}
\rho \frac{D u_{i}}{D t}=-\frac{\partial p}{\partial x_{i}}+\rho G_{i}+\frac{\partial}{\partial x_{j}}\left[2 \eta e_{i j}-\frac{2}{3} \eta\left(\nabla \cdot u_{i}\right) \delta i j\right] \\
\nabla \bullet u=0
\end{gathered}
$$

In the present study, two modes of texturing are introduced. Firstly, surface texturing is placed on the convergent area $\left(0^{\circ}-48^{\circ}\right)$ and secondly, on the divergent area $\left(122^{\circ}-170^{\circ}\right)$. A mesh number of about $90,000-100,000$ nodes for the computational domain was utilized depending on the surface texturing. It should be noted that the meshing process for textured surfaces has been checked to ensure grid independent results. 9,375.94

\section{Results and discussions}

Figure 2 shows the pressure distribution as a fungction texture area $\left(0^{\circ}-48^{\circ}\right)$ on journal bearing with eccentricity ratio of 0.2 and 0.8 . For the eccentricity ratio of 0.2 , the maximum load support is $9.38 \mathrm{kN}$ on the ratio of texture depth is 0.34 . The minimum load support is $5.60 \mathrm{kN}$ on the ratio of texture depth is 6.00 . From the Table 2, it is seen that shallow groove condition gives better load support of deep groove. The load support on smooth condition is 4.99 respectively. Otherwise for the eccentricity ratio of 0.8 , giving the texturing surface decreases the load support. The load support in the smooth condition is $53.22 \mathrm{kN}$, while the minimum load support is $48.29 \mathrm{kN}$ for the ratio of texture depth is 6.00 . Whereas the pressure distribution shows the same trend and condition. 


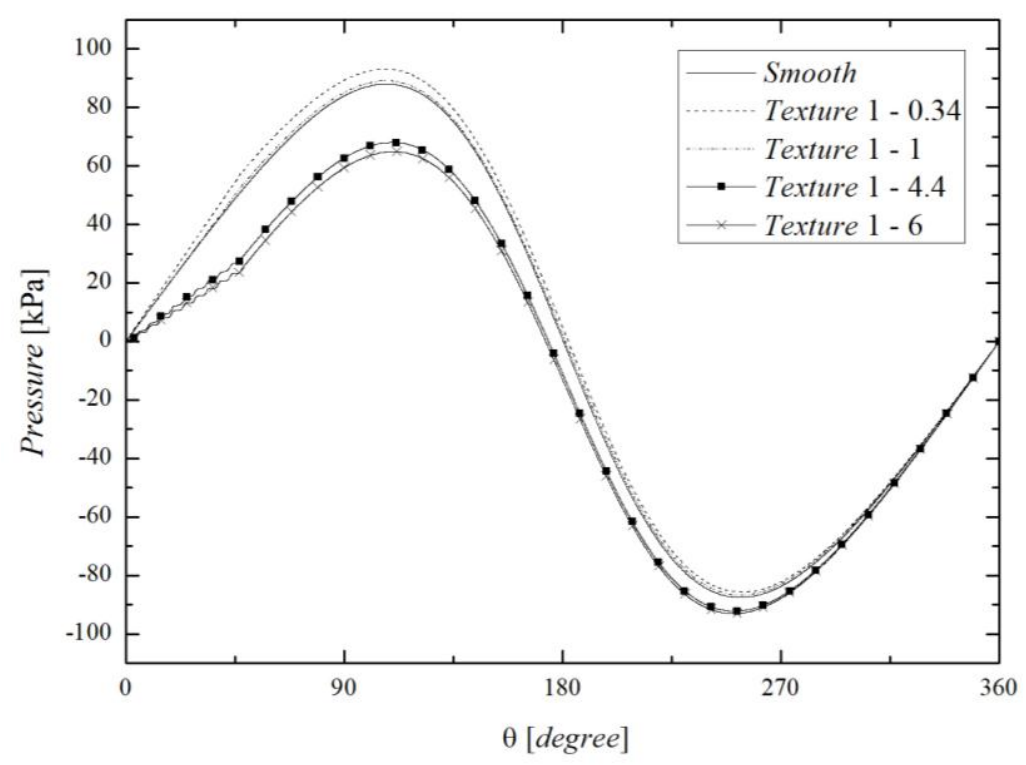

(a)

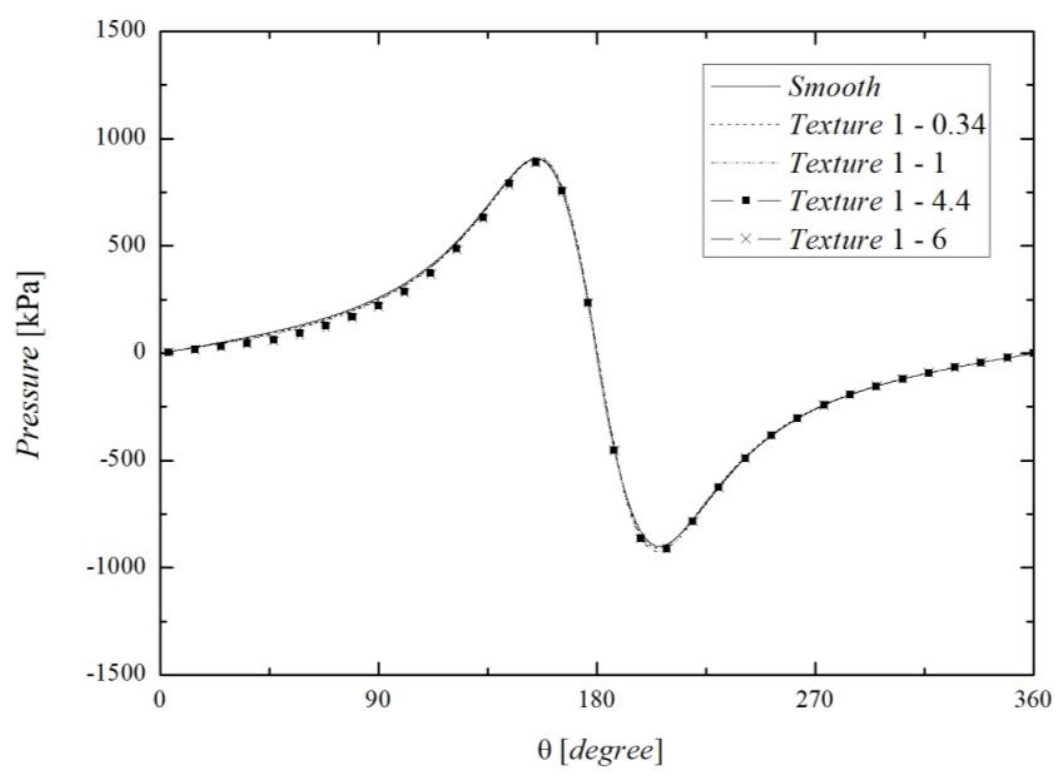

(b)

Fig. 2. The pressure distribution as a function of textured areas $\left(0^{\circ}-48^{\circ}\right)$ on journal bearing (a) The eccentricity ratio 0.2 (b) The eccentricity ratio 0.8 .

Figure 3 depicts the pressure distribution as a function of texture area $\left(122^{\circ}-170^{\circ}\right)$ for the case of eccentricity ratio of 0.2 and 0.8 , respectively. For the eccentricity ratio of 0.2 , giving the surface texturing improves the load support, while the best condition is shallow groove especially when the ratio of texture depth is 1.00 . In this condition, the load support 
is $9.07 \mathrm{kN}$ or it increases $81.76 \%$ when compared to smooth conditions (4.99 $\mathrm{kN})$. While on the eccentricity ratio of 0.8 , by giving surface texturing with shallow groove improves load support. The maximum load suppor is $57.39 \mathrm{kN}$. The opposite trend is found when the surface texturing used is a deep groove. This will decreases the load support. The minimum load support is $49.60 \mathrm{kN}$. While the load support in smooth surface is $53.22 \mathrm{kN}$.

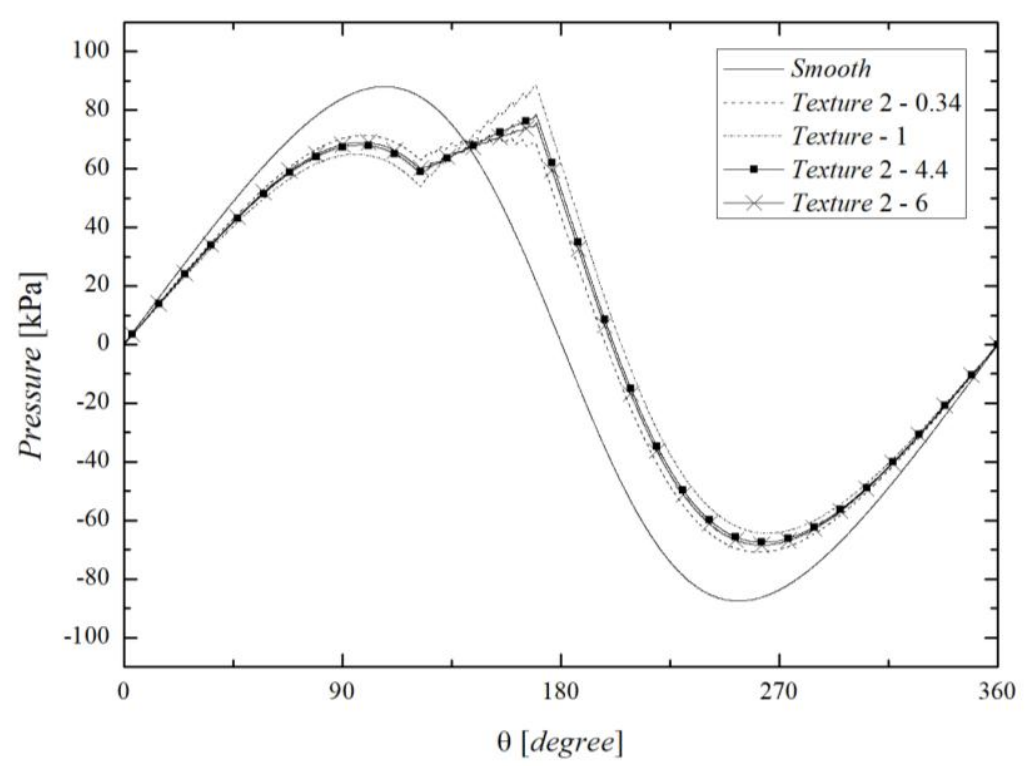

(a)

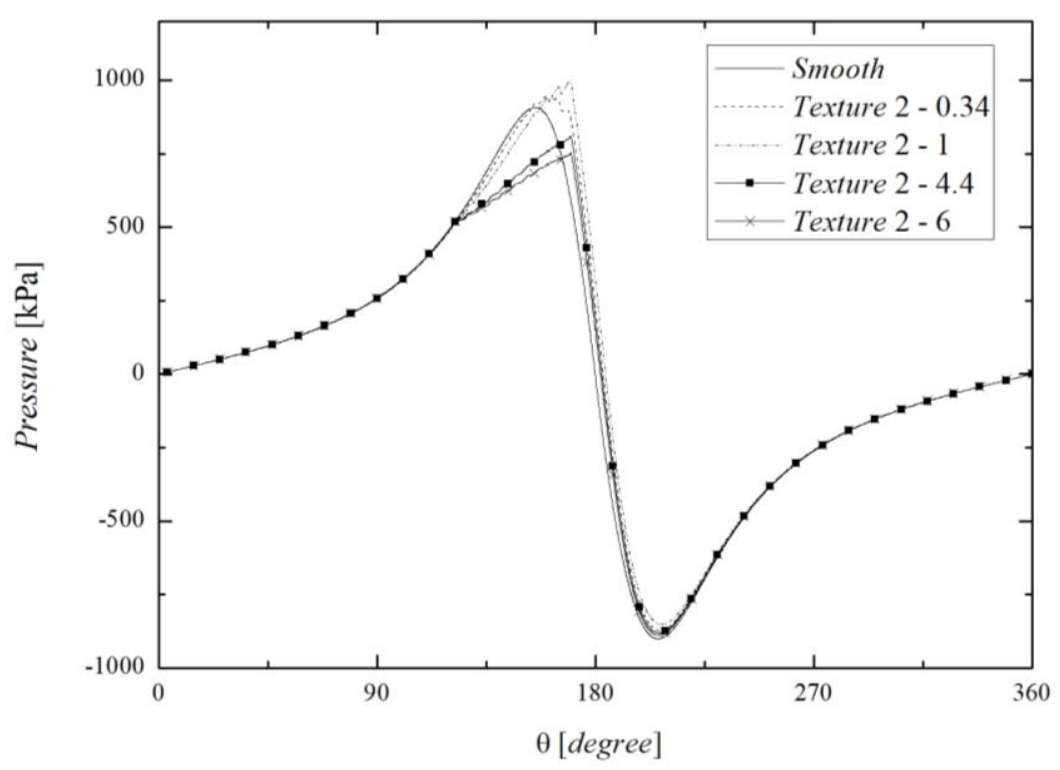

(b)

Fig. 3. The pressure distribution as a function of textured areas $\left(122^{\circ}-170^{\circ}\right)$ on journal bearing (a) The eccentricity ratio 0.2 (b) The eccentricity ratio 0.8 . 
Table 2. Optimized lubricated contact characteristics for different surface texturing.

\begin{tabular}{|c|c|c|c|c|c|}
\hline \multirow{3}{*}{$\begin{array}{c}\text { The ratio of eccentricity } \\
0.2\end{array}$} & & \multicolumn{2}{|c|}{ Texture $1\left(0^{\circ}-48^{\circ}\right)$} & \multicolumn{2}{|c|}{ Texture $2\left(122^{\circ}-170^{\circ}\right)$} \\
\hline & $d / h_{\min }$ & $P(k P a)$ & $W(N)$ & $P(\mathrm{kPa})$ & $W(N)$ \\
\hline & smooth & 88.08 & $4,989.33$ & 88.08 & $4,989.33$ \\
\hline \multirow{2}{*}{$\begin{array}{c}\text { Shallow groove } \\
\left(d / h_{\min } \leq 1\right)\end{array}$} & 0.34 & 93.16 & $9,375.94$ & 71.41 & $8,845.56$ \\
\hline & 1.00 & 89.19 & $8,832.19$ & 88.67 & $9,074.64$ \\
\hline \multirow{2}{*}{$\begin{array}{l}\text { Deep groove } \\
\left(d / h_{\min }>1\right)\end{array}$} & 4.40 & 68.11 & $6,012.18$ & 78.73 & $8,884.72$ \\
\hline & 6.00 & 64.97 & $5,595.00$ & 75.89 & $8,838.23$ \\
\hline \multirow{3}{*}{$\begin{array}{c}\text { The ratio of eccentricity } \\
0.8\end{array}$} & & \multicolumn{2}{|c|}{ Texture $1\left(0^{\circ}-48^{0}\right)$} & \multicolumn{2}{|c|}{ Texture $2\left(122^{\circ}-170^{\circ}\right)$} \\
\hline & $d / h_{\min }$ & $P(k P a)$ & $W(N)$ & $P(\mathrm{kPa})$ & $W(N)$ \\
\hline & smooth & 906.54 & $53,223.45$ & 906.54 & $53,223.45$ \\
\hline \multirow{2}{*}{$\begin{array}{l}\text { Shallow groove } \\
\left(d / h_{\min } \leq 1\right)\end{array}$} & 0.34 & 907.09 & $52,786.57$ & 943.63 & $56,725.55$ \\
\hline & 1.00 & 914.71 & $52,627.67$ & 997.45 & $57,386.90$ \\
\hline \multirow{2}{*}{$\begin{array}{l}\text { Deep groove } \\
\left(d / h_{\min }>1\right)\end{array}$} & 4.40 & 891.47 & $49,240.77$ & 811.39 & $51,263.40$ \\
\hline & 6.00 & 884.95 & $48,289.35$ & 753.45 & $49,595.93$ \\
\hline
\end{tabular}

\section{Conclusions}

In the present study, the effect of surface texturing in a lubricated journal bearing was analyzed. The CFD model based on Navier-Stokes in journal bearing was presented and solved. Based on the explanation discussed earlier, the conclusion can be drawn as follows:

1. For the eccentricity ratio of 0.2 , the surface texturing on the convergent area is able to increase the load support of the journal bearing.

2. For the eccentricity ratio of 0.8 , the surface texturing does not provide an increase in load support.

3. The main finding in this research is the fact that the shallow groove further provides improved lubrication performance of the journal bearing.

\section{References}

1. G. Ryk, Y. Kligerman, I. Etsion, STLE Tribol. Trans. 45, 444 (2002)

2. I. Etsion, G. Halperin, STLE Tribol. Trans. 45, 430 (2002)

3. I. Etsion, G. Halperin, V. Brizmer, Y. Kligerman, Tribol. Lett. 17, 295 (2004)

4. A. Kovalchenko, O. Ajayi, A. Erdemir, G. Fenske, I. Etsion, Tribol. Int. 38, 219 (2005)

5. M. B. Dobrica, M. Fillon, Proc. ImecE Part. J. J. Eng. Tibol. 223, 69 (2009)

6. S. Cupillard, S. Glavatskih, M. J. Cervantes, Proc. ImecE Part. J. J. Eng. Tribol. 224, $751(2010)$

7. S. Yuan, W. Huang, X. Wang, Tribol. Int. 44, 1047 (2011)

8. S. Yagi, N. Katayama, H. Hasegawa, H. Matsushita, S.I. Okihara, T. Kusumoto, A. Tsuboi, Tribol. Online, 10 (5), 390 (2015)

9. K. Yagi, H. Sato. and J. Sugimura, Tribol. Online, 10 (3), 232 (2015) 